\section{Correspondence on 'Machine learning integration of scleroderma histology and gene expression identifies fibroblast polarisation as a hallmark of clinical severity and improvement'}

I read with great interest the article by Showalter et al ${ }^{1}$ who, through an unbiased machine learning approach integrating skin biopsy histology and gene expression, describe the relevance of CD34 and $\alpha$-smooth muscle actin ( $\alpha$-SMA) stains as biomarkers reflecting clinical severity and improvement in patients with diffuse cutaneous systemic sclerosis (dcSSc; scleroderma). Elegantly, the authors have shown that CD34 staining decreases with worsening clinical severity and subsequently increases with clinical improvement, while the opposite was observed for $\alpha$-SMA myofibroblast marker staining. ${ }^{1}$ Moreover, CD34 and $\alpha$-SMA immunostaining intensity appeared to be highly predictive of scleroderma gene expression subsets, with highest CD34 staining and lowest $\alpha$-SMA staining being detectable in normal-like compared with fibroproliferative and inflammatory dcSSc skin samples. ${ }^{1}$ Further analyses revealed that clinically severe dcSSc skin exhibiting the $\alpha$-SMA ${ }^{\text {high }} / \mathrm{CD} 34^{\text {low }}$ immunophenotype associates with a high inflammatory gene expression signature that can reverse over time in patients with clinical improvement, but not in those who do not improve. ${ }^{1}$ Mechanistically, the authors have suggested that differential CD34 and $\alpha$-SMA stains may reflect distinct fibroblast polarisation states, with the $\alpha-\mathrm{SMA}^{\text {high }} / \mathrm{CD} 34^{\text {low }}$ immunophenotype characteristic of clinically severe dcSSc skin samples reflecting a transition from $\mathrm{CD}_{3} 4^{+}$normal fibroblasts to $\alpha-\mathrm{SMA}^{+}$inflammatory fibroblasts/myofibroblasts. ${ }^{1}$ However, it should be considered that gene expression analyses were carried out on whole skin biopsy specimens, which does not allow the identification of the specific cell types expressing relevant target genes, and that double $\alpha$-SMA/CD34 stain would be essential in an attempt to identify transitional fibroblasts expressing both markers. In support of their hypothesis, the authors further discuss that a previous study showed that scleroderma skin displays an inverse staining pattern between CD34 and two other fibroblast markers, namely podoplanin and CD90/ Thy1, and that the proposed fibroblast transition could be induced in vitro in response to proinflammatory cytokines. ${ }^{2}$ In this scenario, I believe another plausible mechanism that can explain the distinctive CD $34^{\text {low }}$ immunophenotype of scleroderma skin is worth mentioning.

Growing evidence indeed indicates that different dermal fibroblast populations do exist and that fibroblast heterogeneity may be crucial in determining skin architecture during development and repair. ${ }^{34}$ Among them, a distinctive stromal cell type named telocyte has been identified in human skin and other tissues/organs over the last decade. ${ }^{5-7}$ Telocytes possess extremely long cytoplasmic processes (telopodes) with a moniliform silhouette and peculiar ultrastructural features and express CD34, being also commonly referred to as telocytes/CD34 ${ }^{+}$stromal cells. ${ }^{5-7}$ By forming extensive interstitial networks with their telopodes, telocytes establish unique spatial relationships with a variety of cell types and are regarded as important actors in the intercellular signalling mechanisms underlying local tissue homeostasis through both cell-to-cell contacts and releasing extracellular vesicles. ${ }^{6}$ Hence, abnormalities in telocyte networks are being increasingly implicated in different pathologies, such as chronic inflammatory and fibrotic conditions, including scleroderma. ${ }^{589}$ In this regard, by means of transmission electron microscopy and CD34 immunostaining, it has been reported that telocytes/CD $34^{+}$stromal cells display severe ultrastructural damages suggestive of ischaemia-induced cell degeneration and are progressively lost from the clinically affected skin of patients with scleroderma. ${ }^{9}$ Of note, telocyte damage and reduction appeared to evolve differently according to scleroderma subsets and stages, being more rapid and severe in dcSSc. ${ }^{9}$ In that study, both the numerous ultrastructural cell injuries detected by electron microscopy and the lack of cells coexpressing CD34 and CD90/Thy1 in double stained skin sections were in favour of a cell degenerative rather than transitional process. ${ }^{9}$ In scleroderma skin, the progressive loss of the telocyte/CD $34^{+}$stromal cell network was suggested to contribute to the altered structure of the extracellular matrix and, possibly, to an impairment in the control of the activity of neighbouring cells, such as fibroblasts/myofibroblasts and mast cells, through disrupted intercellular signalling. ${ }^{9}$

Further, when using CD34 stain, one should always consider that this marker is widely expressed also by endothelial cells of blood microvessels, which are known to be decreased in scleroderma skin. ${ }^{8}$ Thus, the combination of CD31 and CD34 stains has proved to be extremely useful to unequivocally differentiate between $\mathrm{CD} 31^{-} / \mathrm{CD} 34^{+}$stromal cells and $\mathrm{CD} 31^{+} / \mathrm{CD} 34^{+}$microvessels that may often appear as fibroblast-like vascular profiles with no obvious lumen in tissue sections. ${ }^{89}$ Interestingly, a very recent study provided further support to the evidence that human skin telocytes/ CD $34^{+}$stromal cells are a cell population definitely distinct from 'classical' fibroblasts. ${ }^{10}$ In fact, through a two-step immunomagnetic microbead-based method, it was feasible the isolation of three dermal cell populations with different morphologies, namely $\mathrm{CD} 31^{-} / \mathrm{CD} 34^{+}$cells with distinctive features of telocytes, CD $31^{-} / \mathrm{CD} 34^{-}$'classical' fibroblasts and $\mathrm{CD} 31^{+} / \mathrm{CD} 34^{+}$endothelial cells. ${ }^{10}$

Overall, whatever the cause of the decrease in staining, the paper by Showalter et $a l^{1}$ expands previous evidence for a central implication of the CD34 antigen in scleroderma skin pathology $^{29}$ and undoubtedly provides the first demonstration that it might serve as a powerful biomarker of clinical severity and improvement in future clinical trials.

\section{Mirko Manetti $\odot$}

Department of Experimental and Clinical Medicine, Section of Anatomy and Histology, University of Florence, Florence, Italy

Correspondence to Dr Mirko Manetti, Department of Experimental and Clinical Medicine, Section of Anatomy and Histology, University of Florence, Florence 50134, Italy; mirko.manetti@unifi.it

Contributors MM has completely drafted and finalised the manuscript.

Funding The author has not declared a specific grant for this research from any funding agency in the public, commercial or not-for-profit sectors.

Competing interests None declared.

Patient and public involvement Patients and/or the public were not involved in the design, or conduct, or reporting, or dissemination plans of this research.

Patient consent for publication Not required.

Provenance and peer review Not commissioned; internally peer reviewed.

(c) Author(s) (or their employer(s)) 2020. No commercial re-use. See rights and permissions. Published by BMJ.

Check for updates 
To cite Manetti M. Ann Rheum Dis Epub ahead of print: [please include Day Month Year]. doi:10.1136/annrheumdis-2020-219264

Received 8 October 2020

Accepted 11 October 2020

\section{Sinked}

http://dx.doi.org/10.1136/annrheumdis-2020-219292

Ann Rheum Dis 2020;0:1-2. doi:10.1136/annrheumdis-2020-219264

ORCID iD

Mirko Manetti http://orcid.org/0000-0003-3956-8480

\section{REFERENCES}

1 Showalter K, Spiera R, Magro C, et al. Machine learning integration of scleroderma histology and gene expression identifies fibroblast polarisation as a hallmark of clinical severity and improvement. Ann Rheum Dis 2020. doi:10.1136/ annrheumdis-2020-217840. [Epub ahead of print: 07 Oct 2020].
2 Nazari B, Rice LM, Stifano G, et al. Altered dermal fibroblasts in systemic sclerosis display podoplanin and CD90. Am J Pathol 2016;186:2650-64.

3 Driskell RR, Watt FM. Understanding fibroblast heterogeneity in the skin. Trends Cell Biol 2015;25:92-9.

4 Driskell RR, Lichtenberger BM, Hoste E, et al. Distinct fibroblast lineages determine dermal architecture in skin development and repair. Nature 2013;504:277-81.

5 Cretoiu SM, Popescu LM. Telocytes revisited. Biomol Concepts 2014;5:353-69.

6 Kondo A, Kaestner KH. Emerging diverse roles of telocytes. Development 2019;146:dev175018.

7 Kang Y, Zhu Z, Zheng Y, et al. Skin telocytes versus fibroblasts: two distinct dermal cell populations. J Cell Mol Med 2015;19:2530-9.

8 Ibba-Manneschi L, Rosa I, Manetti M. Telocytes in chronic inflammatory and fibrotic diseases. Adv Exp Med Biol 2016;913:51-76.

9 Manetti M, Guiducci S, Ruffo M, et al. Evidence for progressive reduction and loss of telocytes in the dermal cellular network of systemic sclerosis. J Cell Mol Med 2013;17:482-96.

10 Romano E, Rosa I, Fioretto BS, et al. A two-step immunomagnetic microbead-based method for the isolation of human primary skin telocytes/CD34+ stromal cells. Int J Mol Sci 2020;21:5877. 